\title{
Williams-Beuren syndrome: Usual face, unusual heart
}

\author{
Natalia Marin Huarte ${ }^{1}$, Luis García-Guereta ${ }^{2}$, Pablo Lapunzina ${ }^{3}$ \\ ${ }^{1}$ Neonatology Department, Universitary Hospital La Paz, Madrid, Spain \\ ${ }^{2}$ Pediatric Cardiology Department, Universitary Hospital La Paz, Madrid, Spain \\ ${ }^{3}$ Genetics Department, Universitary Hospital La Paz, Madrid, Spain \\ Email: N.marinhuarte@gmail.com
}

Received 4 February 2013; revised 8 March 2013; accepted 17 March 2013

\begin{abstract}
Williams-Beuren Syndrome (WB-S) occurs in approximately $1 / 7500$ live births. It is characterized by typical facial features, congenital heart defects and mild mental retardation. Around $75 \%-80 \%$ of all patients have some kind of cardiovascular disorder being supravalvular aortic stenosis and pulmonary artery stenosis the most frequent. This syndrome is due to a contiguous gene deletion (1- to 2-megabase deletion on the long arm of chromosome 7), including the entire elastin gene and 20 additional genes. We present a case of a two year old boy with WB-S and Tetralogy of Fallot, a very infrequent association. Diagnosis of WB-S could be made because of typical facial features. Characteristic WB-S deletion was present. Genetic study to rule out 22q11 deletion was also performed.
\end{abstract}

Keywords: Williams-Beuren Syndrome; Tetralogy of Fallot; Genetic Diagnosis

\section{INTRODUCTION}

Williams-Beuren Syndrome (WB-S) occurs in approximately $1 / 7500$ live births. It is characterized by typical facial features, congenital heart defects and mild mental retardation. Around $75 \%-80 \%$ of all patients have some kind of cardiovascular disorder with supravalvular aortic stenosis, supravalvular pulmonary stenosis and peripheral pulmonary stenosis accounting for the vast majority of them. We present a case of WB-S and Tetralogy of Fallot (TOF), a very infrequent association. Early diagnosis was possible because of specific facial features, and not because of classic cardiovascular manifestations that usually appear within this syndrome.

\section{CASE REPORT}

A two-year old boy was referred to our unit for surgical treatment with a diagnosis of WB-S and congenital heart disease. He was first studied because of a heart murmur detected at birth. A 2D echocardiography study performed at his original center disclosed a ventricular septal defect and pulmonary stenosis. He remained asymptomatic and without cyanotic spells. WB-S was first suspected at 7 months of age, because of dysmorphic facial features (Figure 1) and hypercalcemia. He was the only child of unrelated parents, without a family history of WB-S or congenital heart disease. A FISH study confirmed 7q11.23 deletion. At one year of age, he was also diagnosed hypothyroidism.

Upon admission to our center, physical examination revealed good general condition, no cyanosis, short anteverted nose, prominent lips and characteristics that resembled those found in patients with WB-S. A loud systolic murmur was heard all over the precordium. Electrocardiography showed right atrial and ventricular hypertrophy and a chest X-ray showed a right aortic arch, normal cardiac size and slightly decreased pulmonary vascularization. 2D Doppler echocardiography showed Tetralogy of Fallot consisting of a ventricular septal

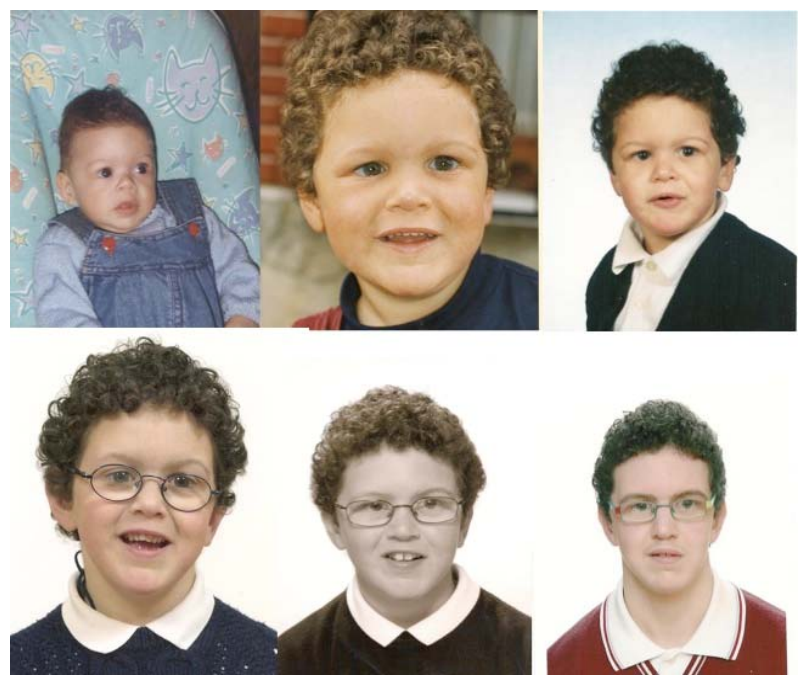

Figure 1. This composite shows six images of the child at different ages. Typical facial appearance in Williams-Beuren syndrome can be noticed since early in life: prominent ears, wide forehead, wide mouth, short nose, full cheeks, periorbital fullness, a broad nasal tip and long philtrum. 
defect, right ventricular hypertrophy, valvular and infundibular pulmonary stenosis, hypoplasia of the left pulmonary branch and mild proximal stenosis of the right pulmonary branch. A mild supravalvular aortic stenosis was also detected. Cardiac catheterization confirmed echocardiographic findings. The patient underwent closure of the ventricular septal defect, relieve of the infundibular stenosis and pulmonary valvulotomy. Further genetic studies confirmed 7q11.23 deletion and ruled out 22q11.2 deletion. Parental genetic studies were normal.

The child is currently 12 years old, required an interventional cath procedure to place a stent to enlarge a proximal right pulmonary artery stenosis (CP Stent 8 ZIG $22 \mathrm{~mm}$ ), he is off drugs, in functional class 1 and has the typical dysmorphic features of WB-S with mild-moderate mental retardation.

\section{DISCUSSION}

Williams-Beuren Syndrome was first described by Dr. J. C. P. Williams in 1961 and Beuren in 1964. This syndrome is characterized by specific facial characters that may resemble an "elfin face", cardiovascular defects and endocrinological abnormalities. A unique neuropsychological profile with developmental delay is almost always present, and other symptoms may also appear. The elfin facies may be a clue to its diagnosis, but these typical facial features are recognizable around 4 - 5 months of age and become clearer during childhood and puberty [1].

This syndrome is due to a contiguous gene deletion (1to 2-megabase deletion on the long arm of chromosome 7 ), including the entire elastin gene and 20 additional genes. The vast majority of patients (>95\%) with WB-S have this deletion, detectable by FISH. The loss of elastin is associated with the cardiovascular abnormalities, the most frequent being supravalvular aortic stenosis and supravalvular pulmonary stenosis, elastin arteriopathy, primary or secondary hypertension and other connective-tissue disorders. Other genes that are typically deleted in people with this syndrome are CLIP2, GTF2I, GTF2IRD1, and LIMK1. The loss of these additional genes presumably account for the non-elastinrelated manifestations of WB-S [2].

Around $75 \%$ - 80\% of all patients with WB-S have some congenital heart defect. Supravalvular aortic stenosis and pulmonary artery stenosis are the most frequent single defects, but any of the systemic and pulmonary arteries can be affected. Other cardiovascular anomalies have been rarely described in association with WB-S including ventricular septal defect, patent ductus arteriosus (PDA), stenosis of systemic arteries, coarctation of the aorta, mitral valve incompetence, and vascular ring. It is not unusual to find an association of several heart lesions in the same WB-S patient. Arterial systemic hypertension is rather frequent in these patients (8\% - 20\%, usually seen in older patients), and all WB-S should be screened periodically. Overall, there are very few cases of WB-S and TOF described in literature [3$6]$.

Most patients are first studied due to dysmorphic features and/or associated heart defects. The typical phenotype of WB-S is difficult to detect in early life and most neonates are identified when typical cardiac defects are present. Eronen et al. studied cardiovascular manifestations in 75 patients with Willams-Beuren disease [6]. They concluded that cardiovascular signs or symptoms were evident in approximately $50 \%$ of their patients when they were newborns. Of these, $77 \%$ were found to have arterial vasculopathy or intracardiac defects, suggesting that typical cardiac anomalies help in making a rapid diagnosis of WB-S when other characteristic features still remain unclear [2]. Physicians should play attention to special facial features, because in certain cases (such as ours) the classical cardiovascular manifestations may not be present and therefore, diagnosis can be delayed. Early diagnosis of this disease is important to initiate treatment for other medical problems that may develop.

It is well known that newborns with congenital heart defects associate chromosomal abnormalities very frequently (12.5\%) [7]. The 22q11.2 deletion may be associated to $8 \%$ - 35\% of cases of Tetralogy of Fallot, it is in fact the most common genetic disorder found in these patients; this genetic disorder is also associated to multiple non-cardiac anomalies. It is important to detect this 22q11 deletion, in order to search for other noncardiac manifestations that frequently accompany this syndrome. In our case, it was a non-related TOF-22q11 deletion [2,8,9]. Fernandez, L. et al. [10] found that when searching for the 22q11 deletion in 819 patients that clinically matched with this deletion, $10.7 \%$ (88 patients) had this deletion, and 3.7\% (30 patients) had other chromosomal anomalies that in most cases, did not imply the 22q11 region. Data reported therefore emphasize on the importance of conventional cytogenetic analysis as an initial genome-wide screening tool in selected patients and highlight the wide genetic variability present in CHD.

We present a case of WB-S with an "unusual heart" but a "usual face" that made early diagnosis possible. Characteristic WB-S deletion was present. Genetic study to rule out 22q11 deletion, was also performed. We highlight the importance of full genetic evaluation by experienced consultants to reach diagnosis of unsuspected chromosomal abnormalities. If these chromosomal abnormalities are found, important implications in reproductive counseling and surveillance for associated ex- 
tracardiac manifestations can be considered.

\section{REFERENCES}

[1] Morris, C.A., Demsey, S.A., Leonard, C.O., Dilts, C. and Blackburn, B.L. (1988) Natural history of Williams syndrome: physical characteristics. The Journal of Pediatrics, 113, 318-326. doi:10.1016/S0022-3476(88)80272-5

[2] Pierpont, M.E., Basson, C.T., Benson, D.W., Gelb, B.D., Giglia, T.M., Goldmuntz, E., McGee, G., Sable, C.A., Srivastava, D. and Webb, C.L. (2007) Genetic basis for congenital heart defects: Current knowledge: A scientific statement from the American Heart Association Congenital Cardiac Defects Committee, Council on Cardiovascular disease in the young: Endorsed by the American Academy of Pediatrics. Circulation, 115, 3015-3038. doi:10.1161/CIRCULATIONAHA.106.183056

[3] Sugayama, S.M., Moisés, R.L., Wagënfur, J., Ikari, N.M., Abe, K.T., Leone, C., da Silva, C.A., Lopes Ferrari Chauffaille Mde, L. and Kim, C.A. (2003) Williams-Beuren syndrome: Cardiovascular abnormalities in 20 patients diagnosed with fluorescence in situ hybridization. Arquivos Brasileiros de Cardiologia, 81, 462-473. doi:10.1590/S0066-782X2003001300003

[4] Del Pasqua, A., Rinelli, G., Toscano, A., Iacobelli, R., Digilio, C., Marino, B., Saffirio, C., Mondillo, S., Pasquini, L., Sanders, S.P. and de Zorzi, A. (2009) New findings concerning cardiovascular manifestations emerging from long-term follow-up of 150 patients with the Williams-Beuren-Beuren syndrome. Cardiology in the Young, 19, 563-567. doi:10.1017/S1047951109990837

[5] Pernot, C., Worms, A.M., Marçon, F. and Admant, P. (1984) Williams-Beuren facies with mental retardation and tetralogy of Fallot. Pediatrie, 39, 53-58.

[6] Eronen, M., Peippo, M., Hiippala, A., Raatikka, M., Arvio, M., Johansson, R. and Kähkönen, M. (2002) Cardiovascular manifestations in 75 patients with Williams syndrome. Journal of Medical Genetics, 39, 554-558. doi:10.1136/jmg.39.8.554

[7] Hartman, R.J., Rasmussen, S.A., Botto, L.D., RiehleColarusso, T., Martin, C.L., Cragan, J.D., Shin, M. and Correa, A. (2011) The contribution of chromosomal abnormalities to congenital heart defects: A populationbased study. Pediatric Cardiology, 32, 1147-1157. doi:10.1007/s00246-011-0034-5

[8] Piran, S., Bassett, A.S., Grewal, J., Swaby, J.A., Morel, C., Oechslin, E.N., Redington, A.N., Liu, P.P. and Silversides, C.K. (2011) Patterns of cardiac and extracardiac anomalies in adults with Tetralogy of Fallot. American Heart Journal, 161, 131-137. doi:10.1016/j.ahj.2010.09.015

[9] Botto, L.D., May, K., Fernhoff, P.M., Correa, A., Coleman, K., Rasmussen, S.A., Merritt, R.K., O’Leary, L.A., Wong, L.Y., Elixson, E.M., Mahle, W.T. and Campbell, R.M. (2003) A population-based study of the 22q11.2 deletion: Phenotype, incidence, and contribution to major birth defects in the population. Pediatrics, 112, 101-107. doi:10.1542/peds.112.1.101

[10] Fernández, L., Lapunzina, P., Pajares, I.L., Palomares, M., Martínez, I., Fernández, B., Quero, J., García-Guereta, L., García-Alix, A., Burgueros, M., Galán-Gómez, E., Carbonell-Pérez, J.M., Pérez-Granero, A., Torres-Juan, L., Heine-Suñer, D., Rosell, J. and Delicado, A. (2008) Unrelated chromosomal anomalies found in patients with suspected 22q11.2 deletion. American Journal of Medical Genetics, 146A, 1134-1141. 